\title{
Report of the Editors of the American Political Science Review, 2008-2009
}

\author{
Ronald Rogowski, Managing Editor \\ for the APSR Editorial Collective
}



e report here on the journal's operations during the year from July 1,2008 , to June 30, 2009. In doing so, we want first to express our thanks to the APSA: its staff, Council, and Publications Committee, both for good advice and for important material support. The impact of both is documented, albeit only partially, in the following article. The APSR Editorial Board and its Executive Committee have also been invaluable, and we have benefited particularly from the concentrated counsel that a subcommittee provided during a two-day site visit to UCLA in July. Editorial Board members have also given unstintingly of their time to serve as guest editors on UCLA-connected submissions that might otherwise raise conflicts of interest. We owe very special debts of gratitude to our Senior Editor, Joseph Riser, whose serene and wise disposition seems never to falter; our graduate editorial assistants (EAs), Megan Gallagher, Diana Ichpekova, Rebekah Sterling, and Matt Spence; two of our original co-editors, Kathleen Bawn and Michael Chwe, who gave extraordinarily dedicated service but decided to leave the group effective July 1, 2009; and Gary Cox (UCSD) and Arthur Lupia (Michigan), who agreed to join our weekly meetings via videoconference-in Gary's case, for the long term; in Skip's, temporarily. Finally, we thank the authors of the nearly 700 papers submitted to us and the over 2,ooo referees who gave, unremunerated and anonymously as always, their astute and often admirably detailed counsel.

\section{SUBMISSIONS AND PROCESSING} The Number of Papers Submitted

The surge of submissions during our initial year, which peaked in the early months of 2007-08 at an annualized rate of almost a thousand and frankly overwhelmed us, tapered off considerably in 2008-09 (table 1). Total submissions (including revise and resubmits) fell from over 800 to about 750 (still over 20\% higher than in Lee Sigelman's final year as Managing Editor), and new submissions declined from close to 800 to just under 700 (almost 30\% higher than in Lee's final year). Continuing a welcome trend from the previous year, more of our new submissions were from scholars outside the United States. Also, the number of revise and resubmits rose, from 51 in $2007-08$ to 64 in 2008-09.

\section{Turnaround Times}

The time between submission and first decision remained higher than we (or our authors) would like but fell by about $10 \%$, from 96 to 88 days (table 2). The major gains were in quicker vetting by the EAs and more prompt responses from our referees. For the former, we again credit APSA for funding an additional EA position (which, we now realize, will probably have to be permanent $t^{1}$, and better performance by more experienced EAs. Our reviewer turnaround has also been a bit quicker; indeed, anticipating delay, refusal, or no response from over a quarter of referees (see below), we have been inviting more reviewers and designating more alternates in the initial round.

\section{The Mix of Submitted Papers}

Categorized by subfield-and recall, this categorization is now done by the authors themselves at the time of submission-the pattern of papers submitted this year continued to hardly differ at all from previous years (table 3a). As was the case in 2007-08, the two new fields, Race, Ethnicity, and Politics and Other, attracted, in total, $11 \%$ of submissions, while the percentage in every other field rose or declined by at most $1 \%$.

The distribution of submissions by
Table 1.

Submissions per Year

\begin{tabular}{lll} 
YEAR & NUMBER OE SUBMISSIONS \\
\hline & Total & New \\
\hline $2008-2009$ & 757 & 693 \\
\hline $2007-2008$ & 829 & 778 \\
\hline $2006-2007$ & 619 & 543 \\
\hline $2005-2006$ & 692 & 596 \\
\hline $2004-2005$ & 623 & 538 \\
\hline $2003-2004$ & 611 & 523 \\
\hline $2002-2003$ & 672 & 546 \\
\hline $2001-2002$ & 615 & 509 \\
\hline $2000-2001$ & 427 & 327 \\
\hline
\end{tabular}

Table 2.

Elapsed Time in Review Process, 2008-09

PHASE OF
REVIEW PROCESS

AVERAGE NUMBER OF CALENDAR DAYS

From receipt to editor assignment 16.3

From editor assignment to first reviewer assigned

From editor assignment to first decision

71.5

From receipt to first decision

87.8 approach (table 3 b), as categorized by the EAs, changed little more: in the current year, a total of $74 \%$ of the papers submitted were classified as formal, quantitative, or some combination of the two, as opposed to $71 \%$ in the previous year. The percentage of "small N" submissions held constant (and small), while that of papers classified as interpretive or conceptual fell by two percentage points. But we wonder increasingly about how to define these categories, and whether they continue to be the most appropriate ones: are articles on electoral fraud in imperial Ger- 
Table $3 a$.

Distribution of Papers Submitted, 2008-2009 (\%)

YEAR

FIELD

\begin{tabular}{|c|c|c|c|c|c|c|c|c|}
\hline & $\begin{array}{c}\text { American } \\
\text { Politics }\end{array}$ & Comparative Politics & $\begin{array}{c}\text { International } \\
\text { Relations }\end{array}$ & $\begin{array}{c}\text { Normative } \\
\text { Theory }\end{array}$ & $\begin{array}{l}\text { Formal } \\
\text { Theory }\end{array}$ & Methods & $\begin{array}{c}\text { Race, Ethnicity, } \\
\text { and Politics }\end{array}$ & Other \\
\hline 2008-2009 & 25 & 22 & 16 & 15 & 8 & 3 & 3 & 8 \\
\hline 2007-2008 & 26 & 21 & 17 & 14 & 7 & 4 & 3 & 8 \\
\hline 2006-2007 & 31 & 31 & 15 & 15 & 5 & 3 & $\mathrm{n} / \mathrm{a}$ & $\mathrm{n} / \mathrm{a}$. \\
\hline 2005-2006 & 37 & 25 & 17 & 15 & 2 & 3 & $\mathrm{n} / \mathrm{a}$ & $\mathrm{n} / \mathrm{a}$ \\
\hline 2004-2005 & 38 & 26 & 15 & 14 & 4 & 4 & $\mathrm{n} / \mathrm{a}$ & $\mathrm{n} / \mathrm{a}$ \\
\hline
\end{tabular}

Table $3 b$.

Distribution of Papers Submitted, 2008-2009 (\%)

YEAR

APPROACH

\begin{tabular}{|c|c|c|c|c|c|c|}
\hline & Formal & Quantitative & Formal and Quantitative & Small N & $\begin{array}{c}\text { Interpretive/ } \\
\text { Conceptual }\end{array}$ & Other \\
\hline 2008-2009 & 12 & 49 & 13 & 2 & 23 & 1 \\
\hline 2007-2008 & 14 & 49 & 8 & 2 & 25 & 2 \\
\hline 2006-2007 & 11 & 55 & 4 & 2 & 24 & 4 \\
\hline $2005-2006$ & 14 & 51 & 5 & 2 & 23 & 4 \\
\hline 2004-2005 & 13 & 52 & 6 & 1 & 27 & 1 \\
\hline
\end{tabular}

many; the political participation of former abductees in Uganda; or the effects of gender quotas in Mumbai, using quantitative methods to analyze micro-level data within a single country, "small" or "large" N? We feel increasingly that some finer-grained method of capturing these distinctions is needed, but we are not yet ready ourselves to suggest one.

\section{OUTCOMES}

The most significant change in the review process was the sharp rise in summary rejections (tables $4 \mathrm{a}$ and $4 \mathrm{~b}$ ), from $6 \%$ of all submissions in $2007-08$ to $16 \%$ (about one in six) in 2008-09. This move, urged upon us in Council discussion last year, parallels what has been happening at other journals and seems to have the desired effects of relieving "reviewer fatigue" and allowing submissions that would almost surely be declined by APSR after the usual review process to be quickly redirected to a more appropriate outlet. Withdrawals declined slightly. The overall result is that this year, only $73 \%$ of submissions continued to full review, in contrast to about $84 \%$ in most previous years.

At the same time, our percentage of revise and resubmits and conditional accepts has risen: the total of both categories as a share of total submissions was 9.1\% in the current year, in contrast to $6.5 \%$ in our first year. We continue in general to follow the previous editorial practice of granting revise and resubmits only where we believe the probability of ultimate acceptance is 0.8 or better; thus, the July 1 st total of some 50 revise and resubmits returned to us may be expected to yield some 40 actual articles.

The array of papers accepted for publication in the current year is categorized by field and approach in tables $5 \mathrm{a}$ and $5 \mathrm{~b}$. In comparing acceptances to submissions by field, normative theory is somewhat overrepresented and American politics slightly underrepresented, but otherwise the deviations are slight. A similar comparison by approach suggests a modest underrepresentation of formal and small-N work (although note the previous caveat) and some overrepresentation of quantitative work, although in the sum of those three fields (formal, quantitative, and formal and quantitative) almost no deviations from the submission rate $-76 \%$ of acceptances vs. $74 \%$ of submissions-were in one of those three fields.

As we did last year and Lee did in each of his years, we urge that these numbers be treated with caution: there is (despite popular conceptions to the contrary) great stochastic variation between years, and the acceptances in a given year will mostly reflect submissions in the previous year. Moreover, our previous year's acceptances were calculated on an unusually small N. We do note, however, for what it is worth, that the share of acceptances categorized as interpretive or conceptual rose from $9 \%$ to $23 \%$ from $2007-08$, while acceptances for quantitative submissions fell from $70 \%$ to $59 \%$.

Table $4 b$.

Outcome of First Round (\%), Previous Year

\begin{tabular}{lc} 
OUTCOME & 2007-2008 \\
\hline $\begin{array}{l}\text { Withdrawn, incorrect } \\
\text { submission }\end{array}$ & 3.2 \\
\hline $\begin{array}{l}\text { Summary reject (without } \\
\text { reviews) }\end{array}$ & 6.1 \\
\hline Reject after reviews & 84.2 \\
\hline Invite R\&R & 5.9 \\
\hline Conditional accept & 0.6 \\
\hline Accept & 0.0 \\
\hline
\end{tabular}


Table $5 a$.

Distribution of Papers Accepted, by Field, 2008-09 (\%)

FIELD

\begin{tabular}{ccccccc}
\hline American Politics Comparative Politics & $\begin{array}{c}\text { International } \\
\text { Relations }\end{array}$ & $\begin{array}{c}\text { Normative } \\
\text { Theory }\end{array}$ & $\begin{array}{c}\text { Formal } \\
\text { Theory }\end{array}$ & Methods & $\begin{array}{c}\text { Race, Ethnicity, and } \\
\text { Politics }\end{array}$ & $\begin{array}{c}\text { Other } \\
\text { 21 }\end{array} 26$ \\
\hline
\end{tabular}

Table $5 b$.

Distribution of Papers Accepted, by Approach, 2008-09 (\%)

APPROACH

\begin{tabular}{cccccc}
\hline Formal & Quantitative & Formal and Quantitative & Small N & Interpretive/Conceptual & Other \\
\hline 5 & 59 & 12 & 0 & 24 & 0 \\
\hline
\end{tabular}

We believe that our efforts to attract and publish manuscripts across all subfields in the discipline have borne fruit. At the same time, we exert our greatest efforts to make sure that as many articles as possible that appear in the Review are comprehensible by and of interest to a broad spectrum of political and other social scientists. Our primary aim remains that of stimulating conversation

and inquiry among the broad community

that is political science.

\section{NOT E S}

1. In the brief period in early 2009 when we had four

EAs, the time from receipt to editor assignment fell

to about 10 days.

\section{Congressional Fellowship Program 2009-2010 Office Assignments}

$\mathrm{F}$ ounded in 1953, the APSA Congressional Fellowship Program is the nation's oldest and most prestigious congressional fellowship. More than 50 years later, the program remains devoted to its original objective of expanding knowledge and awareness of Congress. For nine months, select political scientists, journalists, doctors, federal executives, and international scholars gain "hands on" understanding of the legislative process by serving on congressional staffs. Through this unique opportunity, the association enhances public understanding of policymaking and improves the quality of scholarship, teaching, and reporting on American national politics. For more information, please visit www.apsanet.org/content_3031.cfm?navID=41. The 2010 office assignments are:

\section{U.S. SENATE}

Jason Ackleson, Ph.D.

Sen. Jeff Bingaman (D-NM)

Courtney Cooper

Sen. Blanche Lincoln (D-AR)

Amy K. DiRusso

Sen. Benjamin L. Cardin (D-MD)

Lee Drutman, Ph.D.

Sen. Robert Menendez (D-NJ)

Sheldon D. Fields, Ph.D.

Sen. Barbara Mikulski (D-MD)

Laura Kosch

Sen. Mike Johanns (R-NE)

Gregory Margolis, Ph.D.

Sen. John Rockefeller (D-WV)
Daniel K. Schill, Ph.D.

Sen. Amy Klobuchar (D-MN)

Beth Ward

Sen. Debbie Stabenow (D-MI)

\section{U.S. HOUSE OF REPRESENTATIVES}

Nancy Berson

Rep. Charles Rangel (D-NY)

B. Welling Hall, Ph.D. Rep. Keith Ellison (D-MN)

\section{Sarah Han}

Rep. Bob Inglis (R-SC)

Ulrike Hornung, LL.M.

Rep. Linda T. Sanchez (D-CA)

Sang-hun Lee
Rep. Jim McDermott (D-WA)

Stacia Martin

Rep. Kurt Schrader (D-OR)

Rebecca Thorpe

Rep. James Oberstar (D-MN)

Torsak Janpian

Del.Eni F. H. Faleomavaega (D-American Samoa)/House Committee on Foreign Affairs, Subcommittee on Asia, the

Pacific and the Global Environment

\section{LEADERSHIP OFFICES}

Margaret Wilmoth, Ph.D.

Office of the Speaker

Katrina Gamble, Ph.D. 